\title{
Deeper insights into the moisture-induced hygroscopic and mechanical properties of hemp reinforced biocomposites
}

Samuel Réquilé, Antoine Le Duigou*, Alain Bourmaud and Christophe Baley

Univ. Bretagne Sud, UMR CNRS 6027, IRDL, F-56100 Lorient, France

*corresponding author: antoine.le-duigou@univ-ubs.fr

\begin{abstract}
This article provides deeper insight into moisture sorption over a wide range of relative humidity (RH), from $9 \%$ to $98 \%$, and its effect on the evolution of the tensile behaviour and performance of hemp/epoxy unidirectional biocomposites. Moisture sorption is associated with orthotropic hygroscopic expansion which is also related to the influence of fibre reinforcement distribution and the generation of residual stresses due to manufacturing. Tensile behaviour is significantly modified by moisture content, with a non-linear behaviour becoming more evidenced. The increase of moisture content causes exponential decay of tensile modulus, but a non-monotonic evolution of tensile strength and strain at break shows optimal properties at about 3\%. The hygroscopic property evolution observed is responsible for the creation of compressive radial stresses at the fibre/matrix interface, which promotes load transfer and benefits the interface performance.
\end{abstract}

Keywords: A. Polymer-matrix composites (PMCs), B. Mechanical properties, B. Environmental degradation, B. Fibre/matrix bond.

\section{1-Introduction}

The current ecological trend induces the search for an alternative for the development of composite materials using ligno-cellulosic fibres (e.g. hemp, flax, jute, sisal, and kenaf fibres) as reinforcements. Mainly intended for the paper industry, insulation, textiles, and short fibre-reinforced thermoplastic biocomposites, hemp fibre reinforcements present a potential for valorisation in new and demanding structural or semi-structural applications. However, the development of high performance composites requires an advanced knowledge of their mechanical behaviour in various environments, which is currently lacking in the literature. From observation, and as a consequence of the nature of their 
applications, biocomposite structures are often subjected to changing humid environments during their lifetime. They interact with humid environments because of the hydrophilic properties of the natural fibre reinforcements $[1,2]$. The moisture sensitivity of natural fibres is mainly explained by their complex multi-scale structure and biochemical composition. The fibre cell wall rich in amorphous polysaccharides such as hemicelluloses $(\sim 15 \%)$ and pectins ( $\sim 6 \%)$ [3] induces an important amount of available hydroxyl groups responsible for water sorption [1]. Water diffusion occurs through the penetration of water in the form of vapour or liquid, thus creating bonds with the fibre cell wall (monolayer water) and through micro-capillaries (polylayer water) in a continuous and dynamic process. Besides the increase in fibre weight, water sorption in natural fibres has been identified as the main contributor to their anisotropic swelling, namely the difference in longitudinal and transverse swelling [4,5]. The important water sorption and anisotropic swelling of hemp fibres associated with the low water sorption capacity of a polymer matrix leads to reversible or partially reversible consequences upon biocomposite performance. Several authors have shown the impact of water sorption in natural fibre composites, inducing a change of the material mechanical properties described by physico-chemical processes: polysaccharide leashing [57], hygroscopic stresses [5-7], fibre/matrix interface degradation [8], and hydrolysis and plasticising [9]. Most of the studies examine the influence of liquid water sorption by immersion on the hygroscopic and mechanical properties of biocomposites; these experimental conditions, however, are not sufficient and do not always represent the conditions of use of these materials in an environment with humidity variation. Hence, there is a significant lack of information and analysis of the effect of relative humidity on the performance of biocomposites.

The aim of the present study is to evaluate the influence of absorbed moisture on the hygroscopic and mechanical behaviour of hemp/epoxy unidirectional biocomposites. As a first step, sorption isotherm measurements are carried out and combined with swelling measurements across environments with varying relative humidity, ranging from $9 \%$ to $98 \% \mathrm{RH}$. Second, the effect of moisture on the tensile behaviour and properties of biocomposites is examined and discussed.

\section{2- Materials and methods}

\subsection{Materials}

Hemp fibres (Cannabis Sativa L., cultivars "Fedora 17") were supplied by Fibre Recherche Développement (Troyes, France). Fibres were mechanically extracted from straws harvested by La 
Chanvrière (Bar-sur-Aube, France) at the end of August 2016 after pre-harvesting the seeds and 37 days of field-retting. The thermoset resin is an epoxy system consisting of a DGEBA resin (AXSON Epolam 2020) and an aliphatic amine hardener at a weight ratio of 100:34.

\subsection{Biocomposite manufacturing}

Fibres were extracted and aligned to form a unidirectional bundle of about $10 \mathrm{~cm}$ in length. The bundle was impregnated with epoxy resin for a good fibre/matrix interface [10] and to obtain unidirectional biocomposites with a volume fraction of about 55\%. The impregnated fibre bundles were placed in an aluminium mould of $6 \times 2 \mathrm{~mm}^{2}$ section, open at each end to evacuate the excess of resin during compression. Given the small size of the section, the resin flow was mainly longitudinal and was assumed to have a reduced effect of mis-orientation. The samples were then cured with a temperature cycle of $3 \mathrm{~h}$ at $40{ }^{\circ} \mathrm{C}, 2 \mathrm{~h}$ at $60{ }^{\circ} \mathrm{C}$, then $2 \mathrm{~h}$ at $80{ }^{\circ} \mathrm{C}$, and finally $4 \mathrm{~h}$ at $100{ }^{\circ} \mathrm{C}$ (curing cycle proposed by the supplier).

\subsection{Hygroscopic properties experiments}

Moisture sorption: Samples were first oven-dried for the maximum removal of free and bonded water molecules until a constant weight was reached. The composites were then placed in climatic chambers for storage at a particular relative humidity $(\mathrm{RH})$ and constant temperature $\left(23^{\circ} \mathrm{C}\right)$. Using a saturated salt solution, humidity was controlled and regulated in each of the chambers to reach $9 \%, 33 \%, 75 \%$, and 98\%. A continuous air flow within the chamber allowed homogeneous environment conditions. The samples were periodically removed to be weighed and characterized. The percentage weight gain $\mathrm{M}_{t}$ at saturation was calculated as follows: $M_{t}(\%)=\frac{t \quad 0}{{ }^{\prime}} \times 100$, where $\mathrm{W}_{\mathrm{t}}$ and $\mathrm{W}_{0}$ are the weight of the sample after moisture exposure and the weight of the dry material before moisture exposure, respectively. The maximum moisture sorption was calculated as the average value of five consecutive measurements with a variation below $3 \%$.

Hygroscopic strain: Hygroscopic strain was measured in similar fashion to the weight gain; the measurements were carried out in dry and humid states, using a digital micrometre with a precision of 1 $\mu \mathrm{m}$. Three marks were made along the samples to ensure that the swelling measurements were always performed at the same point. The results were then averaged arithmetically. 
Sorption-desorption cycles: The reversibility of the hygroscopic and mechanical properties was analysed on hemp/epoxy samples. Before testing, the samples were dried as previously described, then stored consecutively at $\mathrm{RH}=50 \%, \mathrm{RH}=98 \%$, and again at $\mathrm{RH}=50 \%$. Each storage step occurred at $\mathrm{T}=23^{\circ} \mathrm{C}$, and the hygroscopic stability was verified before changing the samples to a different environment.

\subsection{Characterisation of tensile properties}

Tensile tests on hemp/epoxy UD biocomposites were performed using a 5566 Instron testing machine at controlled temperature $\left(23^{\circ} \mathrm{C}\right.$ and $\left.\mathrm{RH}=50 \%\right)$ with a crosshead speed of $1 \mathrm{~mm} / \mathrm{min}$. Mechanical tests were performed on dry and humid samples that had reached their saturation time. A $10 \mathrm{kN}$ force sensor was used to measure the load, and an axial extensometer with a nominal length of $25 \mathrm{~mm}\left(\mathrm{~L}_{0}\right)$ was used to measure the strain. Tangent modulus was measured between $0.05 \%$ and $0.15 \%$ strain [11].

\subsection{Scanning electron microscope observation}

The samples were sputter-coated with a thin layer of gold in an Edwards Sputter Coater and analysed with a Jeol JSM 6460LV scanning electron microscope at $20 \mathrm{kV}$ accelerating voltage.

\section{3-Results and interpretation}

\subsection{Hygroscopic properties of hemp/epoxy biocomposites}

\subsubsection{Sorption isotherms}

The evolution of the moisture content of hemp/epoxy UD biocomposites at steady state as a function of water activity for a temperature of $23^{\circ} \mathrm{C}$ is presented in Figure 1.A. Moisture sorption $\left(\mathrm{M}_{\mathrm{t}}\right)$ is measured from samples stored under different relative humidity $(\mathrm{RH})$ environments corresponding to water activity $\left(a_{w}\right)$ ranging from 0.09 to 0.98 . It should be recalled that for any given water activity, the stabilisation of the mass of the sample was reached for each measurement. The sigmoidal shape of the sorption curve can be categorised as a type II according to the classification of the different types of sorption isotherms given by the International Union of Pure and Applied Chemistry (IUPAC). This type of isothermal sorption curve is characteristic of a multi-molecular adsorption during which water molecules accumulate layer by layer [12]; it is generally observed when examining water sorption on hydrophilic cellulosic composites and to a larger extent on plant fibre composites $[13,14]$. 
Given the behaviour of the curves, sorption isotherms can be described using the Park mathematical model according to the following formula:

Equation 1

with $\mathrm{M}_{\mathrm{t}}$ : equilibrium moisture content for a specific water activity $\mathrm{a}_{\text {water }}$, $\mathrm{A}_{\mathrm{L}}$ : Langmuir capacity constant (specific site concentration on the material), $\mathrm{b}_{\mathrm{L}}$ : Langmuir affinity constant, $\mathrm{k}_{\mathrm{H}}$ : Henry solubility constant, $\mathrm{K}_{\mathrm{a}}$ : Equilibrium constant for clustering reaction, $\mathrm{n}_{\mathrm{a}}$ : number of water molecules per cluster.

The contribution of each parameter is different in the specific range of water activity corresponding to the three sorption mechanisms of the Park model. It is important to note that these modes give only a simplified interpretation of the phenomenon occurring in the real system in continuous evolution. The Langmuir sorption mode $\left(\mathrm{a}_{\text {water }}<0.1\right)$ is physically observed when a monolayer of water molecules (or bonded water) is adsorbed on specific sites at the fibre surface or in micro-cavities. The second region $\left(0.1<\mathrm{a}_{\text {water }}<0.5\right)$ defines a linear regression with a slope of the isotherm and shows the absorption of polylayer water (or free water) that occurs when saturation of specific sites is reached. New sorption sites are then created, which leads to diffusion of water in the free volume network, responsible for capillarity mechanisms. In this region, the presence of water molecules increases the fibre swelling. The last region is characterized by high water activity $\left(\mathrm{a}_{\text {water }}>0.5\right)$. The important increase in moisture sorption is linked to a clustering and capillarity phenomenon of water molecules in the system.

Figure 1.A shows that the hemp/epoxy moisture uptake increases progressively with water activity up to a maximal value of $7.6 \pm 0.3 \%$. To understand the contribution of moisture sorption within the material, a moisture sorption test was conducted separately on both the reinforcement and the matrix (Figure 1.B). The evolution of moisture sorption of raw hemp fibres also presents a sigmoidal shape and reaches $20.9 \pm 2.1 \%$ at $\mathrm{a}_{\mathrm{w}}=0.98$. The epoxy matrix reaches a moisture sorption of $2.7 \pm 0.1 \%$ at $\mathrm{a}_{\mathrm{w}}=0.98$. Moisture sorption of the fibres is therefore the main contributor to the global moisture sorption of the composite, despite a non-negligible hydrophilic behaviour of epoxy resin. At high humidity levels, the important increase of composite moisture sorption can be correlated with a similar behaviour of the raw fibres. A similar behaviour has been observed in the literature on cellulosic fibres and attributed to water molecules clustering owing to the presence of surface tension forces in capillary free space in the composite $[15,16]$. It is important to note that the global moisture sorption of the composite is not directly the moisture 
sorption of both constituents. A compressive stress state is induced during moisture sorption by the constraining effect of the matrix on the fibres, thus limiting their hygroscopic expansion [7].

\subsubsection{Hygroscopic strains}

Associated with moisture sorption, a variation in the sample volume is generally observed. Figure 2 shows the sigmoidal evolution of transverse $\left(\Delta \varepsilon_{\mathrm{y}}\right)$, out of plane $\left(\Delta \varepsilon_{\mathrm{z}}\right)$, and volumic $\left(\Delta \varepsilon_{\mathrm{V}}\right)$ hygroscopic strain of hemp/epoxy biocomposites with increasing water activity. The longitudinal strain $\left(\Delta \varepsilon_{\mathrm{x}}\right)$ is neglected as values are too low to overcome the measurement error. This is due to the low microfibrillar angle of hemp fibres that causes important longitudinal stiffness [17,18]. At the fibre scale, moisture is absorbed in the cell wall, causing anisotropic swelling with a maximum reaching around $20 \%$, as seen in previous studies on flax fibres $[6,19,20]$. The moisture sensitive constituents are mainly pectins and hemicelluloses present in fibre bundles and the amorphous region of single fibres [21]. The complex architecture within fibres plays an important role in the anisotropic swelling of the fibre that is globally slaved by the S2 layer with its high longitudinal stiffness induced by the microfibrillar angle [22]. When embedded in a polymeric matrix, the swelling of natural fibres is drastically reduced but still contributes significantly to the hygroscopic strain of the biocomposites [23].

Several studies have reported a linear evolution between hygroscopic strains and mean moisture content, which helps determine a hygroscopic swelling coefficient $(\beta)$ in a specific ply direction. In Figure 2.B., hygroscopic strains vary non-linearly with moisture content up to about $1.2 \%$ followed by a linear trend until reaching maximum moisture content. The deviation of the linear behaviour has already been observed in unidirectional biocomposites and is possibly related to damage-induced sorption [7,24]. In both swelling directions, the generated hygroscopic stresses are possibly higher than the composite transverse strength, which leads to potential damage creating more free volume and modifying the sorption behaviour and water molecules localization within the material.

Unlike the transverse isotropic swelling of hemp fibres, orthotropic swelling is observed at the biocomposite scale. Along the full range of water activity, hygroscopic strain in the out-of-plane direction is twice as high as in the transverse direction. The effect of sample geometry was analysed as the biocomposites present exhibit a drastically thinner thickness than width (ratio width/thickness $=3$ ). Table. 1 gives the moisture sorption at $\mathrm{RH}=98 \%$ of samples showing a different width over thickness 
ratio: $3.0,1.5$, and 1.0. All samples show similar moisture sorption of around $8.5 \%$ at equilibrium. However, an important difference can be observed in terms of hygroscopic strains. The decrease of the width/thickness ratio leads to a more important orthotropic swelling.

In addition, a change of the fibre-fibre distance in the out-of-plane direction during manufacturing appears to be due to the applied pressure in the out-of-plane direction, especially since the width over thickness ratio is high. During composite compression and before resin curing, the excess liquid resin tends to diffuse out of the mould through the open sides, causing a possible heterogeneous distribution of resin (Figure 3.B). Thus, a possible higher fibre surface over resin surface ratio in the out-of-plane direction could occur, leading to a more important swelling of the overall structure in this same direction. An image analysis (not presented in this paper) shows that the fibre surface/resin surface ratio and thus the fibre volume fraction in both $\mathrm{y}$ and $\mathrm{z}$ directions was found to be different $\left(\mathrm{Vf}_{\mathrm{y}}=50.2 \pm 1.1 \%\right.$ and $\left.\mathrm{Vf}_{\mathrm{z}}=58.7 \pm 1.2 \%\right)$. This explains the orthotropic swelling of biocomposites as their swelling is function of fibre content [25]. Figure 3 describes the scenario of the orthotropic swelling of biocomposites.

\subsection{Hygro-mechanical properties}

\subsubsection{Tensile behaviour}

A typical stress/strain $(\sigma-\varepsilon)$ curve and the tangent modulus evolution, for a hemp/epoxy UD biocomposite at ambient humidity (50\%) are shown in Figure 4.A. The $\sigma-\varepsilon$ curve and the tangent modulus evolution can be divided into two distinct regions $\left(\mathrm{E}_{1}\right.$ and $\left.\mathrm{E}_{2}\right)$ according to a range of deformation with an inflection point at around $0.2 \%$ strain. At this point, a change of slope occurs, followed by a quasi-linear relationship between stress and strain before a slight increase in modulus up to material failure. The composite stiffness is lower in the second part of the curve. This result is now well established in the literature. Poilane et al. (2014) [26], Chilali et al. (2017) [27], and Bourmaud et al. (2016) [28] obtained similar results that are explained by the response of the elastic and viscoelastic behaviour of natural fibres. Hemp fiber tensile behavior been described in the literature by many authors (Pickering et al. (200); Placet et al. (2014); Duval et al. (2011)) and for flax (Baley et al. (2002); Andersons et al. (2005); Aslan et al. (2011); Charlet et al. (2009)). A first linear part with a quasi-constant tangent modulus is observed up to a yield point $(\varepsilon \approx 0.2 \%)$, beyond which a strong decrease in stiffness if observed. A second inflection point appears at higher deformation $(\varepsilon \approx 0.7 \%)$, and followed by an increase in stiffness until 
failure. This non-linearity has been attributed to the re-orientation of the cellulosic micro-fibrils of cellulose (present in fiber cell wall) with respect to fiber axis, when subjected to tensile load. At the unidirectional composite scale, mechanical properties are governed by the reinforcement, i.e. hemp fibers. Considering a strong fiber/matrix interface, the mechanical behavior of the reinforcements will be transcribed at the composite scale during tensile loading, highlighted by an increase in tangent modulus with increasing strain.

Figure 4.B shows the evolution of tangent modulus as a function of the applied strain for hemp/epoxy biocomposites after moisture saturation at relative humidity ranging from $9 \%$ to $98 \%$. It is clear that moisture sorption alters the overall biocomposite behaviour, namely its non-linearity. Even if, regardless of the applied strain, a global drop of modulus is always observed from $9 \%$ to $98 \% \mathrm{RH}$, after the inflection point and as a result of the increase of moisture content, the tangent modulus of the material has a tendency to increase.

A first observation relates to the inflection point. As relative humidity increases, a shift of the tangent modulus stabilization appears towards lower strains and reflects early damage initiation. Moreover, the increase in tangent modulus in the second part of the curve is amplified with the increase in relative humidity and moisture content. At $9 \% \mathrm{RH}$, the slope of the $\mathrm{E}_{\mathrm{L}}=\mathrm{f}(\varepsilon)$ function between $\mathrm{E}_{\mathrm{L} . \mathrm{min}}$ and $\mathrm{E}_{\mathrm{L} . \max }$ is negligible, and the tangent modulus is quasi-constant until failure is reached. Increasing the relative humidity from to $33 \%, 50 \%$, and $75 \%$ leads to an increase in the $\mathrm{E}_{\mathrm{L}}=\mathrm{f}(\varepsilon)$ slope to $4.4,5.9$, and 6.3 , the maximum slope obtained over the range of relative humidity studies. A decrease of the slope down to 5.7 is then observed for $98 \% \mathrm{RH}$ and could be due to a change in moisture sorption behaviour (as seen in section 3.1.1) and load transfer degradation.

At the composite scale, this non-linear behaviour is mainly due to the expression of the tensile behaviour of natural fibres triggered by moisture, which facilitates molecular motions within the cell wall. The mechanical behaviour of natural fibres and its non-linearity is hygro-activated with the increase in moisture content [29]. Interestingly, this mechanism illustrates the conservation of the loading transfer ability at the fibre/matrix interface.

\subsubsection{Relationship between tensile properties and moisture sorption}


Reasoning in terms of moisture content rather than of relative humidity enables us to establish the hygromechanical behaviour of biocomposites intrinsically. Figure 5 shows the evolution of tangent modulus, tensile strength, and strain at break for unidirectional hemp/epoxy biocomposites and pure epoxy as a function of moisture content in the humidity range from $9 \%$ to $98 \% \mathrm{RH}$. All tested samples are represented in Figure 5 because each sample is a different system in which even a slight variation of microstructure or composition may alter the hygroscopic behaviour.

The moisture sorption of epoxy resin is not negligible and impacts the mechanical properties at the composite scale. Thus, a slight reduction of the tangent modulus of $13 \%$ is observed from $9 \%$ to $98 \% \mathrm{RH}$, reaching a value of about $3.4 \pm 0.2 \mathrm{GPa}$. Tensile strength and strain at break show a monotonic increase of $25 \%$ and $34 \%$ from $\mathrm{RH}=9 \%$ to $\mathrm{RH}=98 \%$ related to a plasticizing effect of the matrix [30].

For composites, an increase of moisture content leads logically to a monotonic reduction of the tangent modulus. This hygroscopic behaviour is well described by an exponential decay function $\left(\mathrm{R}^{2}=0.988\right)$, which provides useful information to predict the use of composites in real environments; this aspect is currently lacking in the literature. A weight gain greater than $3 \%$ causes a decrease in stiffness of about $50 \%$. For higher moisture sorption $(\approx 8 \%)$ corresponding to a relative humidity of $98 \%$, the longitudinal stiffness reaches $6.2 \pm 1.3 \mathrm{GPa}$. This behaviour, associated with the evolution of the matrix properties, may be attributed to the softening of the material leading to a general increase of the mobility of the molecular chains at the matrix, fibre, and fibre/matrix interface, and consequently a decrease in composite stiffness. Values of longitudinal stiffness of hemp/epoxy composites in immersion, not shown in this paper, confirm this low value. Indeed, after reaching saturation state in immersion, stiffness reaches $3.5 \pm 1.2$ GPa.

The reversibility of the mechanical properties change over moisture content was analysed to identify moisture-induced phenomena. Table 2 shows the tangent modulus evolution during a sorption/desorption cycle (50\% - 98\% - 50\% RH). Tensile tests after the sorption/desorption cycle indicate the nonreversibility of degradation with the tangent modulus, which is reduced by $35 \%$ as compared to the initial value. Basically, irreversible damages should be argued, but as evidenced in Table 2, moisture content after the sorption/desorption test $(50 \% \mathrm{RH})$ is not similar to that of the initial hygroscopic condition even though relative humidity is similar. Careful attention must be paid as the presence of a hysteresis is 
commonly observed between sorption and desorption isotherms is case of natural fibres [31]. Owing to the evolution of stiffness with moisture content (Figure 5.A), it is possible to show that biocomposites with a moisture content of $3.3 \%$ have similar properties during sorption and desorption.

Unlike biocomposite stiffness, tensile strength and strain at break properties vary non-monotonically with moisture content; this aspect is also not dealt with in the literature. Figure 5 shows an increase of $40 \%$ and $101 \%$ between $9 \% \mathrm{RH}$ and $75 \% \mathrm{RH}$ for tensile strength and strain at break. Beyond this point, properties at break are potentially reduced considerably. Therefore, both tensile strength and strain at break show optimal properties at about $3 \%$ moisture sorption, corresponding to samples stored at $75 \%$ relative humidity. In this material state, tensile strength reaches an average value of $261 \pm 29 \mathrm{MPa}$ and strain at break reaches $2.11 \pm 0.14 \%$.

Two hypotheses can account for the optimal performance observed. First, at the fibre scale, several studies have shown plasticization of the samples with the increase of moisture content, thus promoting the realignment of cellulosic microfibrils and giving rise to an increase of fibre stiffness in a similar humidity range [29] [32]. The second hypothesis formed for this evolution of biocomposite performance deals with a modification of stress transfer at the interfaces and more particularly at the fibre/matrix interface level. As stated in section 3.1.2, moisture sorption in hemp biocomposites leads to an important fibre transverse swelling compared to the matrix itself. The very few studies that have determined the hygroscopic expansion coefficient of epoxy resin by direct measurement have found a value between 0.1 and 0.5 $[33,34]$. The hygroscopic expansion for natural fibres stands at 1.14 [6] and confirms the differential swelling obtained. In addition, the fibre moisture uptake results within the composite and on their own are different (see section 3.1.1) due to internal stress [7]. Tensile behaviour thus shows an increasingly significant non-linearity, illustrating the behaviour of natural fibres that indicates an optimal stress transfer. The increase of relative humidity and moisture content leads to a modification of the hygroscopic stress state with the creation of radial compressive stresses by the differential swelling between the fibres and the matrix. This hygroscopic stress state has been observed with hygromorph MAPP or PP biocomposites [7,24]. It has also been quantified in the literature using asymmetric laminates and has shown the production of radial stresses at the interface, hence promoting interface performance results [6] similar to those found in this study. 
Beyond the optimal moisture content, properties at break are reduced considerably, potentially due to several mechanisms such as (1) the reduction of hydrogen bonding at the fibre/matrix interface due to competition with water molecules, (2) plasticizing of the fibre and the middle lamella in fibre bundles because the strong water affinity of pectines and pectates present at the cellular junction reduces the overall reinforcement cohesion [21], and (3) global composite plasticizing that may relieve the hygroscopic stresses. Fractography images (Figure 6) show the fracture surface of hemp/epoxy biocomposites after tensile testing for $9 \% \mathrm{RH}$ and $98 \% \mathrm{RH}$. At $9 \% \mathrm{RH}$, a brittle fracture of the epoxy matrix and hemp fibres is observed with very little decohesion of the fibre/matrix interfaces (Figure 6.A and C). However, increasing the RH leads to a global decohesion of the structure and a more ductile fracture. Low inter-fibre cohesion is observed due to the degradation of the middle lamellae through the presence of moisture, as stated previously (Figure 6.B). Finally, fibre debonding occurring during tensile testing is also visible and leaves holes (white arrows) within fibre bundles (Figure 6.D). The SEM image confirms this phenomenon due to the presence of a common middle lamella between the two holes and visible neighbouring fibre surface. These damages have previously been observed by several authors and indicate the loss of properties when reaching high RH mostly due to a limiting shear transfer at the fibre/fibre interface as well as the fibre/matrix interface [35-38].

\section{Conclusion}

Aimed at increasing understanding of the effect of moisture on biocomposites, which is not properly described in the literature yet, this study has focused on the hygroscopic and mechanical performance of hemp fibre-based composites. Hemp/epoxy unidirectional composites were submitted to a wide range of humid environments $(9 \%, 33 \%, 50 \%, 75 \%$, and $98 \%)$ at a constant temperature of $23^{\circ} \mathrm{C}$. Associated with moisture sorption, and along the full range of water activity, orthotropic hygroscopic expansion was observed with a higher out-of-plane strain in comparison with transverse (and longitudinal) strain. This behaviour was found to be related to the influence of the composite structure (geometry), on the distribution of fibre reinforcement and the generation of compressive stresses due to manufacturing. The tangent modulus reflects the non-linear behaviour of the $\sigma-\varepsilon$ curve of hemp/epoxy biocomposites associated with the intrinsic properties of natural fibres. Beyond the well-known reduction of stiffness with moisture due to plasticization, the tensile behaviour exhibits non-linearity that is increasingly present with high humidity. Stress transfer is therefore still efficient, despite moisture. 
Moreover, both tensile strength and strain show optimal properties at $75 \%$ relative humidity $\approx \approx 3 \%$ moisture content in the material). These results have been related to an increase in natural fibre performance and to the dominating hygroscopic swelling of hemp fibres as compared to the matrix. The increase in moisture content in the material leads to the creation of compressive radial stresses at the fibre/matrix interface and therefore an increase in adhesive pressure. These stresses are generated during moisture sorption by the hygroscopic expansion of the fibres, and more specifically by the differential swelling between the fibre and the matrix. The load transfer may therefore be promoted and be beneficial to the interface performance until a moisture threshold is reached, about $3 \%$. Beyond, a reduction of all the tensile properties is observed. SEM observations suggest a degradation of the fibre/fibre interface and fibre/matrix interface as the main damage mechanism induced by moisture. However, both matrix and fibre cracks also appear over longer periods. To extend the results of this study, it is planned to examine the contribution of the fibre/matrix properties and moisture-induced hygroscopic stresses at the interface to the evolution of the composite performance.

\section{Acknowledgements}

The authors are grateful to ADEME for their financial assistance for the project.

\section{Declarations of interest: none}

\section{References}

[1] Hill CAS, Norton A, Newman G. The water vapor sorption behavior of natural fibers. J Appl Polym Sci 2009;112:1524-37. doi:10.1002/app.29725.

[2] Azwa ZN, Yousif BF, Manalo AC, Karunasena W. A review on the degradability of polymeric composites based on natural fibres. Mater Des 2013;47:424-42. doi:10.1016/j.matdes.2012.11.025.

[3] Liu M, Fernando D, Daniel G, Madsen B, Meyer AS, Ale MT, et al. Effect of harvest time and field retting duration on the chemical composition, morphology and mechanical properties of hemp fibers. Ind Crops Prod 2015;69:29-39. doi:10.1016/j.indcrop.2015.02.010. 
[4] Joffre T, Wernersson ELG, Miettinen A, Luengo Hendriks CL, Gamstedt EK. Swelling of cellulose fibres in composite materials: Constraint effects of the surrounding matrix. Compos Sci Technol 2013;74:52-9. doi:10.1016/j.compscitech.2012.10.006.

[5] Le Duigou A, Requile S, Beaugrand J, Scarpa F, Castro M. Natural fibres actuators for smart bioinspired hygromorph biocomposites. Smart Mater Struct 2017;26:125009. doi:10.1088/1361665X/aa9410.

[6] Le Duigou A, Merotte J, Bourmaud A, Davies P, Belhouli K, Baley C. Hygroscopic expansion: A key point to describe natural fibre/polymer matrix interface bond strength. Compos Sci Technol 2017;151:228-33. doi:10.1016/j.compscitech.2017.08.028.

[7] Péron M, Célino A, Castro M, Jacquemin F, Le Duigou A. Study of hygroscopic stresses in asymmetric biocomposite laminates. Compos Sci Technol 2019;169:7-15. doi:10.1016/j.compscitech.2018.10.027.

[8] Le Duigou A, Davies P, Baley C. Exploring durability of interfaces in flax fibre/epoxy microcomposites. Compos Part A Appl Sci Manuf 2013;48:121-8. doi:10.1016/j.compositesa.2013.01.010.

[9] Alix S, Philippe E, Bessadok A, Lebrun L, Morvan C, Marais S. Effect of chemical treatments on water sorption and mechanical properties of flax fibres. Bioresour Technol 2009;100:4742-9. doi:10.1016/j.biortech.2009.04.067.

[10] Coroller G, Lefeuvre A, Le Duigou A, Bourmaud A, Ausias G, Gaudry T, et al. Effect of flax fibres individualisation on tensile failure of flax/epoxy unidirectional composite. Compos Part A Appl Sci Manuf 2013;51:62-70. doi:10.1016/j.compositesa.2013.03.018.

[11] Bensadoun F, Vallons KAM, Lessard LB, Verpoest I, Van Vuure AW. Fatigue behaviour assessment of flax-epoxy composites. Compos Part A Appl Sci Manuf 2016;82:253-66. doi:10.1016/j.compositesa.2015.11.003.

[12] Alix S, Lebrun L, Marais S, Philippe E, Bourmaud A, Baley C, et al. Pectinase treatments on technical fibres of flax: Effects on water sorption and mechanical properties. Carbohydr Polym 2012;87:177-85. doi:10.1016/j.carbpol.2011.07.035. 
[13] Brunauer S, Deming LS, Deming WE, Teller E. On a Theory of the van der Waals Adsorption of Gases. J Am Chem Soc 1940;62:1723-32. doi:10.1021/ja01864a025.

[14] Guicheret-Retel V, Cisse O, Placet V, Beaugrand J, Pernes M, Boubakar ML. Creep behaviour of single hemp fibres. Part II: Influence of loading level, moisture content and moisture variation. J Mater Sci 2015;50:2061-72. doi:10.1007/s10853-014-8768-0.

[15] Chen H, Miao M, Ding X. Influence of moisture absorption on the interfacial strength of bamboo/vinyl ester composites. Compos Part A Appl Sci Manuf 2009;40:2013-9. doi:10.1016/j.compositesa.2009.09.003.

[16] Moudood A, Hall W, Öchsner A, Li H, Rahman A, Francucci G. Effect of Moisture in Flax Fibres on the Quality of their Composites. J Nat Fibers 2017;0478:1-16. doi:10.1080/15440478.2017.1414651.

[17] Shah DU. Developing plant fibre composites for structural applications by optimising composite parameters: A critical review. J Mater Sci 2013;48:6083-107. doi:10.1007/s10853-013-7458-7.

[18] Lee JM, Pawlak JJ, Heitmann JA. Longitudinal and concurrent dimensional changes of cellulose aggregate fibrils during sorption stages. Mater Charact 2010;61:507-17. doi:10.1016/j.matchar.2010.02.007.

[19] Pejic BM, Kostic MM, Skundric PD, Praskalo JZ. The effects of hemicelluloses and lignin removal on water uptake behavior of hemp fibers. Bioresour Technol 2008;99:7152-9. doi:10.1016/j.biortech.2007.12.073.

[20] Pucci M, Liotier P, Seveno D, Fuentes C, Van Vuure AW, Drapier S. Swelling of flax fibers : effect of thermal treatment on their dimensional stability. Eccm 17 2016;26-30 june:26-30.

[21] Thygesen A, Daniel G, Lilholt H, Thomsen AB. Hemp Fiber Microstructure and Use of Fungal Defibration to Obtain Fibers for Composite Materials. J Nat Fibers 2006;2:19-37. doi:10.1300/J395v02n04_02.

[22] Rafsanjani A, Stiefel M, Jefimovs K, Mokso R, Derome D, Carmeliet J. Hygroscopic swelling and shrinkage of latewood cell wall micropillars reveal ultrastructural anisotropy. J R Soc Interface 2014;11:20140126-20140126. doi:10.1098/rsif.2014.0126. 
[23] Joffre T, Neagu RC, Bardage SL, Gamstedt EK. Modelling of the hygroelastic behaviour of normal and compression wood tracheids. J Struct Biol 2014;185:89-98.

doi:10.1016/j.jsb.2013.10.014.

[24] Le Duigou A, Keryvin V, Beaugrand J, Pernes M, Scarpa F, Castro M. Humidity responsive actuation of bioinspired hygromorph biocomposites (HBC) for adaptive structures. Compos Part A Appl Sci Manuf 2019;116:36-45. doi:10.1016/j.compositesa.2018.10.018.

[25] Le Duigou A, Castro M. Evaluation of force generation mechanisms in natural, passive hydraulic actuators. Sci Rep 2016;6:18105. doi:10.1038/srep18105.

[26] Poilâne C, Cherif ZE, Richard F, Vivet A, Doudou B Ben. Polymer reinforced by flax fibres as a viscoelastoplastic material 2014;112:100-12. doi:10.1016/j.compstruct.2014.01.043.

[27] Chilali A, Zouari W, Assarar M, Kebir H, Ayad R. Effect of water ageing on the load-unload cyclic behaviour of flax fibre-reinforced thermoplastic and thermosetting composites. Compos Struct 2017;183:309-19. doi:10.1016/j.compstruct.2017.03.077.

[28] Bourmaud A, Le Duigou A, Gourier C, Baley C. Influence of processing temperature on mechanical performance of unidirectional polyamide 11-flax fibre composites. Ind Crops Prod 2016;84:151-65. doi:10.1016/j.indcrop.2016.02.007.

[29] Placet V, Cisse O, Boubakar ML. Influence of environmental relative humidity on the tensile and rotational behaviour of hemp fibres. J Mater Sci 2012;47:3435-46. doi:10.1007/s10853-0116191-3.

[30] Jedidi J, Jacquemin F, Vautrin A. Accelerated hygrothermal cyclical tests for carbon/epoxy laminates. Compos Part A Appl Sci Manuf 2006;37:636-45. doi:10.1016/j.compositesa.2005.05.007.

[31] Patera A, Derome D, Griffa M, Carmeliet J. Hysteresis in swelling and in sorption of wood tissue. J Struct Biol 2013;182:226-34. doi:10.1016/j.jsb.2013.03.003.

[32] Stamboulis A, Baillie CA, Peijs T. Effects of environmental conditions on mechanical and physical properties of flax fibers. Compos Part A Appl Sci Manuf 2001;32:1105-15. doi:10.1016/S1359-835X(01)00032-X. 
[33] Lin YC. Investigation of the moisture-desorption characteristics of epoxy resin. J Polym Res 2006;13:369-74. doi:10.1007/s10965-006-9053-y.

[34] Shirangi MH, Michel B. Mechanism of Moisture Diffusion, Hygroscopic Swelling, and Adhesion Degradation in Epoxy Molding Compounds. In: Fan XJ, Suhir E, editors. Moisture Sensit. Plast. Packag. IC Devices, Boston, MA: Springer US; 2010, p. 29-69. doi:10.1007/978-1-4419-5719-1.

[35] Dhakal HN, Zhang ZY, Richardson MOW. Effect of water absorption on the mechanical properties of hemp fibre reinforced unsaturated polyester composites. Compos Sci Technol 2007;67:1674-83. doi:10.1016/j.compscitech.2006.06.019.

[36] Regazzi A, Corn S, Ienny P, Bénézet JC, Bergeret A. Reversible and irreversible changes in physical and mechanical properties of biocomposites during hydrothermal aging. Ind Crops Prod 2016;84:358-65. doi:10.1016/j.indcrop.2016.01.052.

[37] Li Y, Xue B. Hydrothermal ageing mechanisms of unidirectional flax fabric reinforced epoxy composites. Polym Degrad Stab 2016;126:144-58. doi:10.1016/j.polymdegradstab.2016.02.004.

[38] Le Duigou A, Davies P, Baley C. Seawater ageing of flax/poly(lactic acid) biocomposites. Polym Degrad Stab 2009;94:1151-62. doi:10.1016/j.polymdegradstab.2009.03.025. 


\section{Figure captions}

Figure 1: (A) Water vapour isotherm at $23^{\circ} \mathrm{C}$ of hemp/epoxy biocomposites. The Park model is used to fit experimental data, deconvoluted, into Langmuir (1), Henry (2), and clustering (3) sorption modes. (B) Water sorption isotherm for raw hemp fibres and epoxy resin.

Figure 2: A) Transverse $\left(\Delta \varepsilon_{\mathrm{y}}\right)$, out-of-plane swelling $\left(\Delta \varepsilon_{\mathrm{z}}\right)$ and volumic $\left(\Delta \varepsilon_{\mathrm{V}}\right)$ hygroscopic strain of hemp/epoxy biocomposites over a range of water activity 0.09 and 0.98 . B) Hygroscopic strain as a function of moisture sorption. Sigmoidal functions are used to fit experimental data.

Figure 3: Schematic representation of dimensional variation of hemp/epoxy biocomposites at the initial state (A), after manufacturing and curing (B), and after increasing the relative humidity (C). (For the colour version of this figure, consult the web version of this article)

Figure 4: A) Typical stress/strain curve and tangent modulus evolution of a hemp/epoxy biocomposite at $50 \%$ relative humidity. B) Evolution of tangent modulus with the longitudinal strain of hemp/epoxy biocomposites saturated at different relative humidity levels: 9\%, 33\%, 50\%, 75\%, 98\%. (For the colour version of this figure, consult the web version of this article)

Figure 5: Evolution of tangent modulus (A), tensile strength (B), and strain at break (C) as a function of moisture sorption for hemp/epoxy biocomposites. (For the colour version of this figure, consult the web version of this article)

Figure 6: Fractography images (photos and SEM) of hemp/epoxy unidirectional biocomposites at RH=9\% (A and C) and $\mathrm{RH}=98 \%(\mathrm{~B}$ and $\mathrm{D})$.

\section{Table captions}

Table 1: Hygroscopic properties of hemp/epoxy biocomposites showing a different width over thickness ratio and resulting anisotropy $\Delta \varepsilon_{\mathrm{y}} / \Delta \varepsilon_{\mathrm{z}}$.

Table 2: Moisture sorption and mechanical properties evolution during a sorption/desorption cycle of hemp/epoxy biocomposites. $\sigma$ is the tensile strength, $\varepsilon$ the strain at break, and $\mathrm{E}_{\mathrm{L}}$ the tangent modulus. 


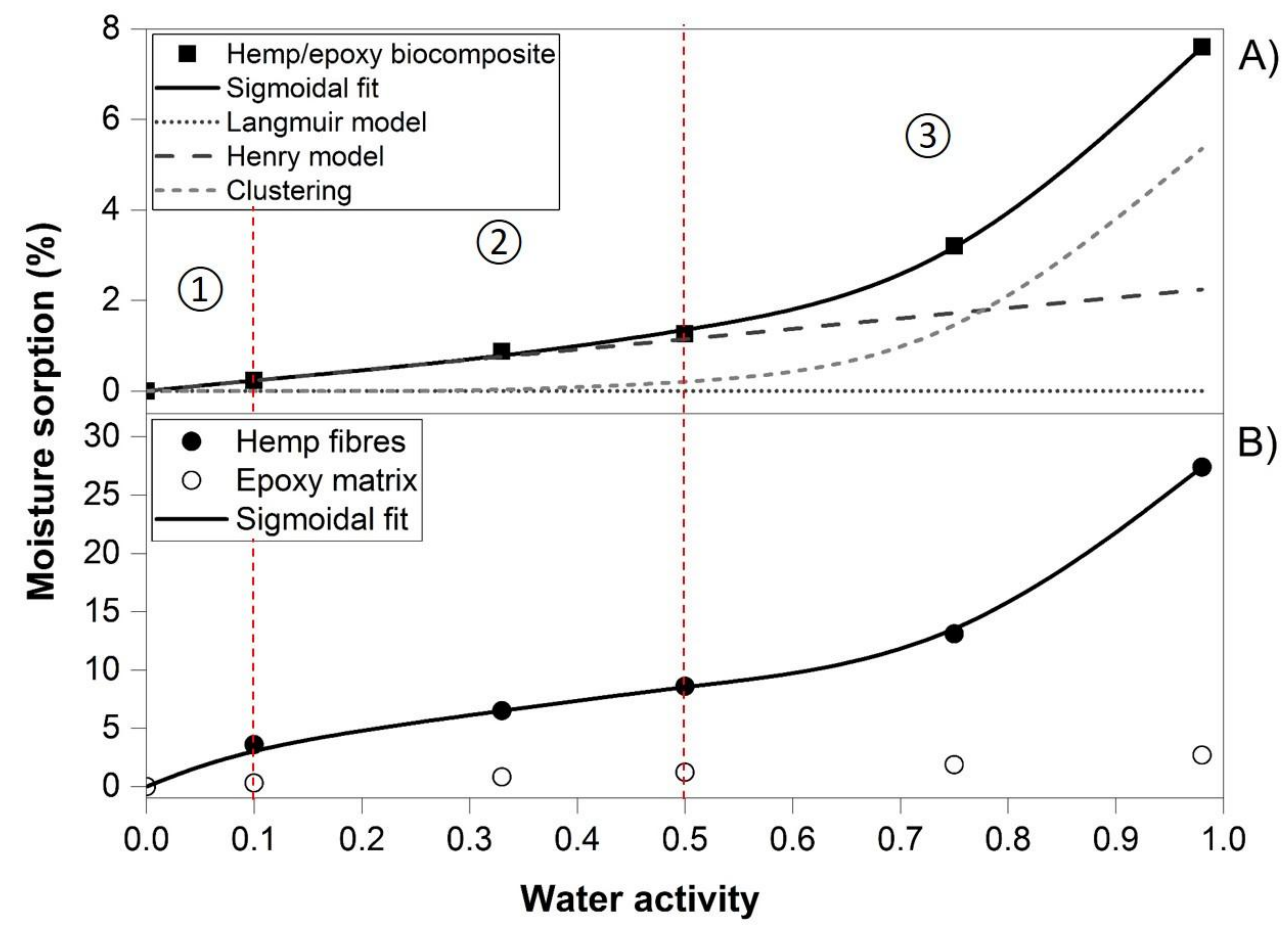

Figure 1: (A) Water vapour isotherm at $23^{\circ} \mathrm{C}$ of hemp/epoxy biocomposites. The Park model is used to fit experimental data, deconvoluted, into Langmuir (1), Henry (2), and clustering (3) sorption modes. (B) Water sorption isotherm for raw hemp fibres and epoxy resin. 

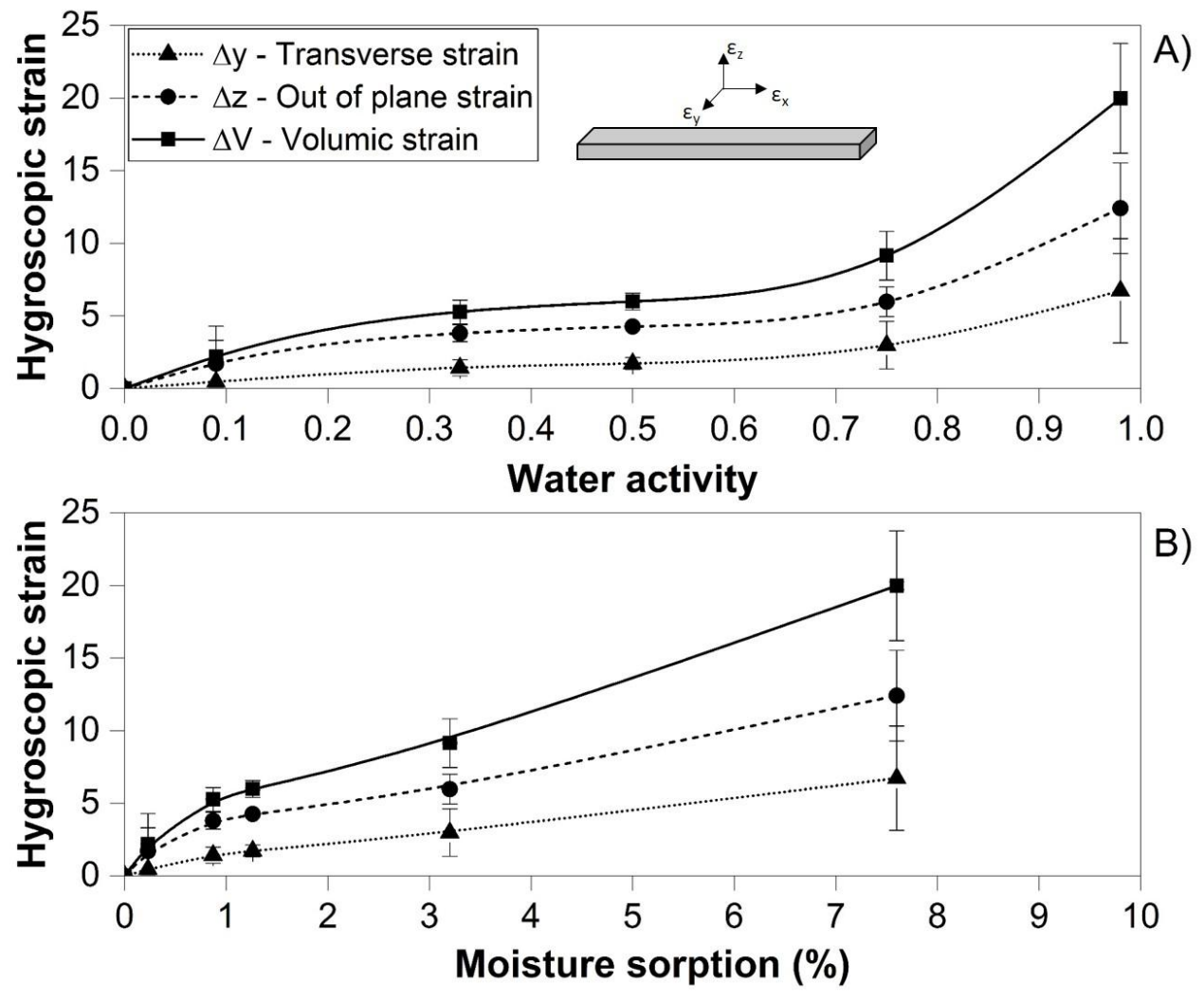

B)

Figure 2: A) Transverse $\left(\Delta \varepsilon_{y}\right)$, out-of-plane swelling $\left(\Delta \varepsilon_{z}\right)$ and volumic $\left(\Delta \varepsilon_{\mathrm{V}}\right)$ hygroscopic strain of hemp/epoxy biocomposites over a range of water activity 0.09 and 0.98 . B) Hygroscopic strain as a function of moisture sorption. Sigmoidal functions are used to fit experimental data. 
A. Initial hemp/epoxy composite

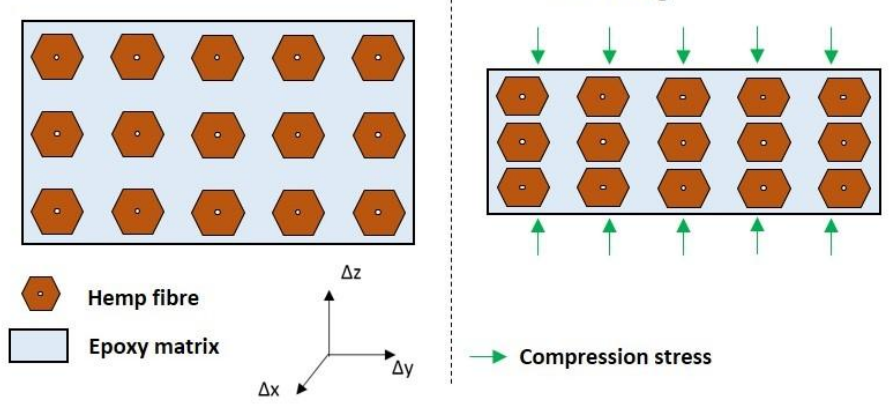

C. Relative humidity increase

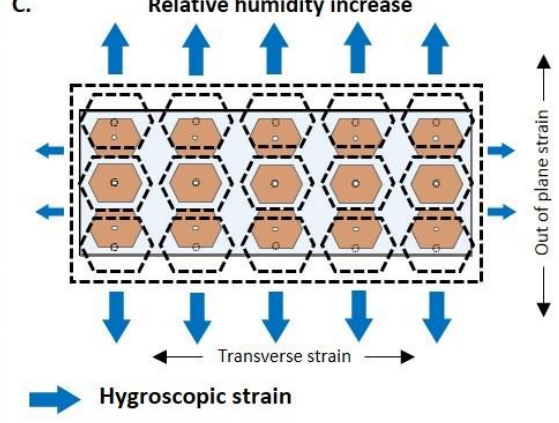

Figure 3: Schematic representation of dimensional variation of hemp/epoxy biocomposites at the initial state (A), after manufacturing and curing (B), and after increasing the relative humidity (C). (For the colour version of this figure, consult the web version of this article) 

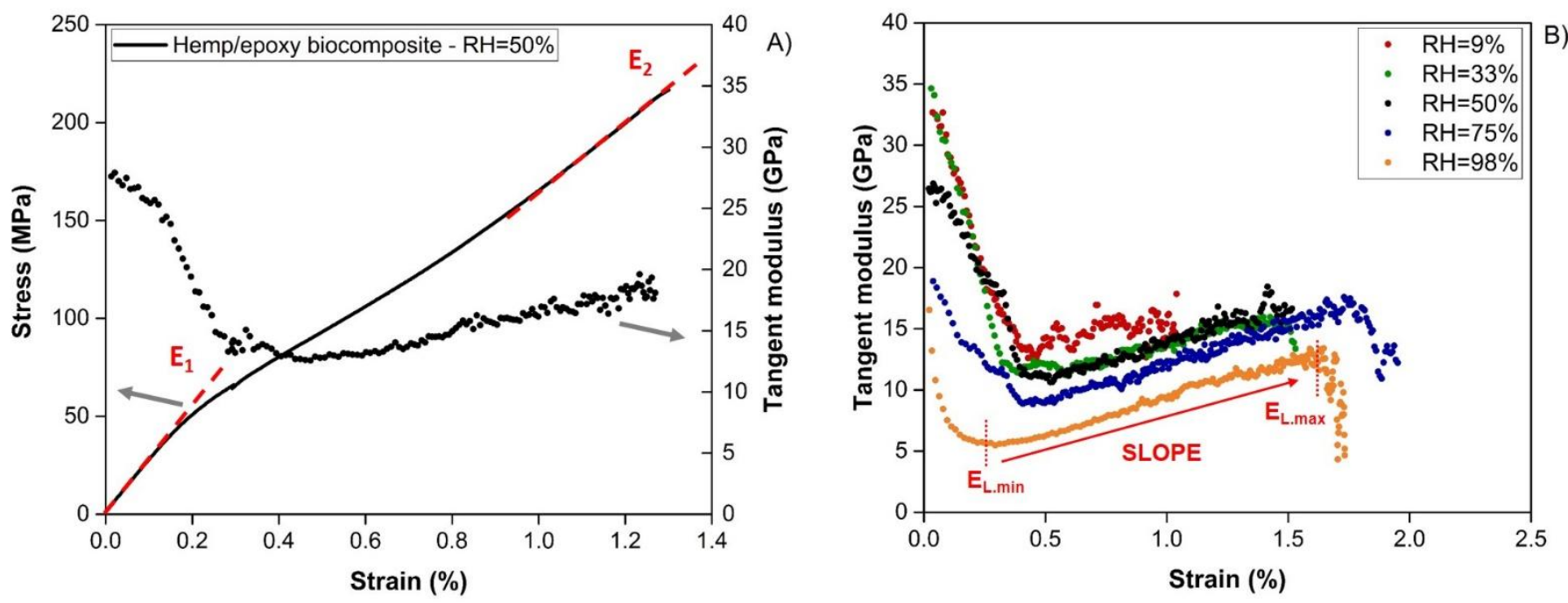

Figure 4: A) Typical stress/strain curve and tangent modulus evolution of a hemp/epoxy biocomposite at 50\% relative humidity. B) Evolution of tangent modulus with the longitudinal strain of hemp/epoxy biocomposites saturated at different relative humidity levels: 9\%, 33\%, 50\%, 75\%, 98\%. (For the colour version of this figure, consult the web version of this article) 

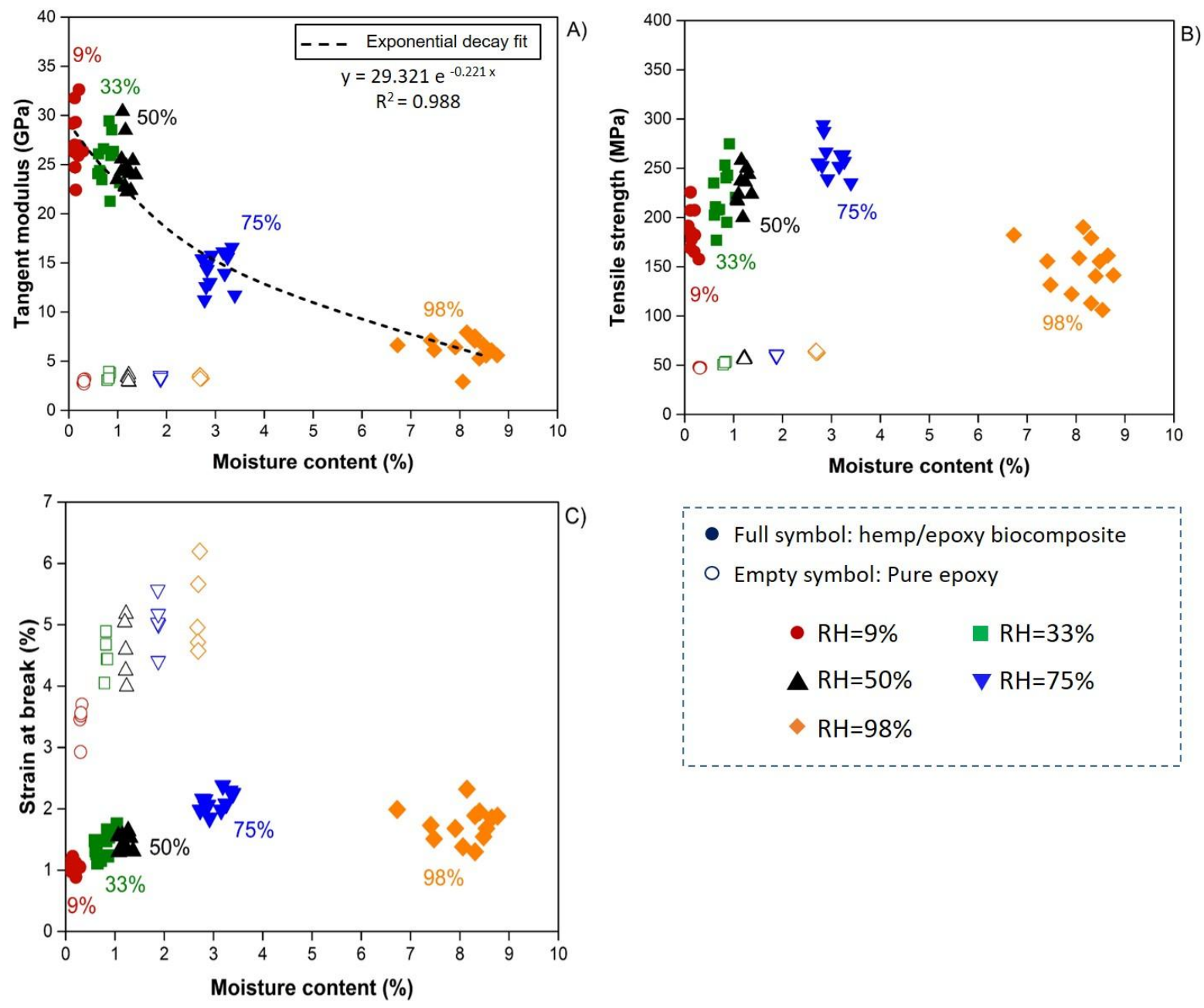

- Full symbol: hemp/epoxy biocomposite

Empty symbol: Pure epoxy

- $\mathrm{RH}=9 \%$ $\mathrm{RH}=33 \%$

$\Delta \mathrm{RH}=50 \% \quad \nabla \mathrm{RH}=75 \%$

- $\mathrm{RH}=98 \%$

Figure 5: Evolution of tangent modulus (A), tensile strength (B), and strain at break (C) as a function of moisture sorption for hemp/epoxy biocomposites. (For the colour version of this figure, consult the web version of this article) 


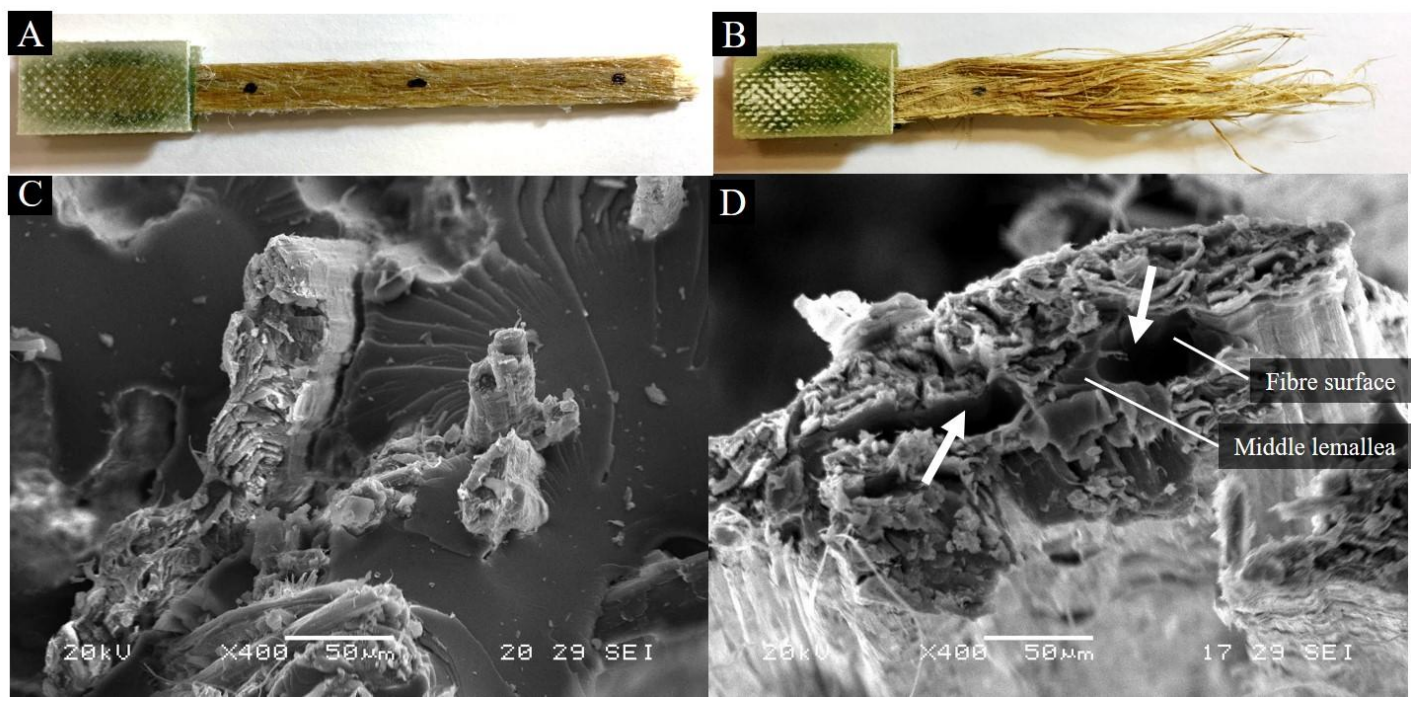

Figure 6: Fractography images (photos and SEM) of hemp/epoxy unidirectional biocomposites at RH=9\% (A and C) and $\mathrm{RH}=98 \%(\mathrm{~B}$ and $\mathrm{D})$. 


\begin{tabular}{cccccc}
\hline & $\begin{array}{c}\text { Width } / \\
\text { Thickness }\end{array}$ & $\begin{array}{c}\Delta \mathbf{m} \\
(\boldsymbol{\%})\end{array}$ & $\begin{array}{c}\Delta \boldsymbol{\varepsilon}_{\mathrm{y}} \\
(\boldsymbol{\%})\end{array}$ & $\begin{array}{c}\Delta \boldsymbol{\varepsilon}_{\mathrm{z}} \\
(\boldsymbol{\%})\end{array}$ & $\Delta \boldsymbol{\varepsilon}_{\mathrm{y}} / \Delta \boldsymbol{\varepsilon}_{\mathrm{z}}$ \\
\hline \multirow{3}{*}{$\begin{array}{c}\text { Hemp/epoxy } \\
\text { biocomposites }\end{array}$} & 3.0 & $8.53 \pm 1.22$ & $4.27 \pm 0.29$ & $6.45 \pm 0.62$ & $0.67 \pm 0.11$ \\
\cline { 2 - 6 } & 1.7 & $8.48 \pm 1.07$ & $3.54 \pm 0.40$ & $4.22 \pm 0.52$ & $0.84 \pm 0.01$ \\
\cline { 2 - 6 } & 1.0 & $8.51 \pm 0.42$ & $2.80 \pm 0.15$ & $2.83 \pm 0.37$ & $1.01 \pm 0.19$ \\
\end{tabular}

Table 3: Hygroscopic properties of hemp/epoxy biocomposites showing a different width over thickness ratio and resulting anisotropy $\Delta \varepsilon_{\mathrm{y}} / \Delta \varepsilon_{\mathrm{z}}$. 


\begin{tabular}{lccc}
\hline $\mathbf{R H}$ & $\mathbf{5 0 \%}$ & $\mathbf{9 8 \%}$ & $\mathbf{5 0 \%}$ \\
\hline $\boldsymbol{\Delta} \mathbf{m}(\mathbf{\%})$ & $1.1 \pm 0.1$ & $8.5 \pm 0.2$ & $3.3 \pm 0.1$ \\
\hline $\boldsymbol{\sigma}(\mathbf{M P a})$ & $223 \pm 22$ & $149 \pm 26$ & $172 \pm 18$ \\
\hline $\boldsymbol{\varepsilon}(\mathbf{\%})$ & $1.43 \pm 0.13$ & $1.75 \pm 0.28$ & $1.51 \pm 0.27$ \\
\hline $\mathbf{E}_{\mathbf{L}}(\mathbf{G P a})$ & $24.7 \pm 2.4$ & $6.2 \pm 1.3$ & $15.9 \pm 2.6$ \\
\hline
\end{tabular}

Table 4: Moisture sorption and mechanical properties evolution during a sorption/desorption cycle of hemp/epoxy biocomposites. $\sigma$ is the tensile strength, $\varepsilon$ the strain at break, and $\mathrm{E}_{\mathrm{L}}$ the tangent modulus. 